\title{
Plano de benefícios como fator motivacional: estudo em empresa familiar do setor metalúrgico
}

\section{Benefit as a motivational factor: study in family company of the metallurgical sector}

\author{
TAYSE GOMES* \\ VALDIRENE GASPARETTO** \\ DARCI SCNORRENBERGER*** \\ ROGÉRIO JOÃO LUNKES ${ }^{* * * *}$
}

\section{RESUMO}

O estudo objetiva averiguar se o plano de benefícios individuais possui potencial motivacional entre os colaboradores de uma empresa do ramo metalúrgico de controle do tipo familiar. Por meio da análise de conteúdo, o trabalho desenvolveu-se em duas etapas: a primeira partiu de um levantamento feito com o administrador a fim de verificar se a companhia oferecia um plano de incentivos; a segunda consistiu na aplicação de questionário aos níveis estratégico, tático e operacional, com a finalidade de detectar a relação entre a implantação de um plano de benefícios e a motivação pessoal. A amostra foi composta por 23 colaboradores, representando $88 \%$ da população. A primeira constatação foi a de que a organização ainda não oferece benefícios de qualquer natureza. Percebeu-se também que os resultados indicam uma

* Universidade Federal de Santa Catarina. Mestranda em Contabilidade na Universidade Federal de Santa Catarina - UFSC. taysegomes_@hotmail.com.

** Professora do curso de Ciências Contábeis da Universidade Federal de Santa Catarina. valdirenegasparetto@gmail.com.

*** Professor do curso de Ciências Contábeis da Universidade Federal de Santa Catarina. darcisc@gmail.com.

**** Professor do curso de Ciências Contábeis da Universidade Federal de Santa Catarina. rogeriolunkes@hotmail.com. 
preferência por benefícios ligados à saúde - o plano de saúde é o preferido por $65 \%$ da amostra. Por outro lado, ninguém considerou importante a ginástica laboral e o auxílio funeral. Apesar dessa preferência, todos gostariam de ter a liberdade de escolher seus benefícios. Quando a amostra é estratificada por estado civil, constata-se que os casados (61\%) entendem que a implementação dos benefícios afetaria positivamente sua motivação, contra $39 \%$ dos solteiros.

Palavras-chave: contabilidade; remuneração; benefícios; motivação.

\section{ABstract}

The objective of this study is to determine if the individual benefits plan has a motivational potential with the employees of a metallurgical company that controls the family type. Through content analysis, the work was developed in two stages: the first one was based on a survey with the administrator to verify if the company offered an incentive plan; the second one consisted of the application of a questionnaire at the strategic, tactical and operational levels in order to detect the relationship between the implementation of a Benefits plan and personal motivation. The sample consisted of 23 employees, representing $88 \%$ of the population. The first finding of the study was that the organization still does not offer benefits of any nature. It was also noticed that the results indicated a preference for health-related benefits, with the health plan being preferred by $65 \%$ of the sample. On the other hand, no one considered work gymnastics and funeral assistance important. Despite this preference, everyone would like the freedom to choose their benefits. When the sample is stratified by marital status, married couples (57\%) understand that the implementation of the benefits would positively affect their motivation, whereas $44 \%$ of singles.

Keywords: accounting; compensation; benefits; motivation.

\section{INTRODUÇÃo}

Em meio às constantes inovações dos cenários econômico e empresarial, as corporações devem estar atentas às descobertas que possam contribuir para o clima organizacional. Fatores como número de colaboradores, idade, sexo, estado civil, funções, escolaridade 
e experiência das equipes, entre outros, vêm sendo estudados por diversos autores, muitos dos quais já constataram que influenciam o nível de satisfação atribuído para os benefícios recebidos (REIS NETO, 2004; CAMINHA, 2012; GHENO; BERLITZ, 2011; KERBER; SCHNEIDER, 2012; ASSALIN; ARANHA, 2010; CARVALHO; MENEZES, 2013). Se esses aspectos não forem considerados torna-se cada vez mais difícil alinhar os interesses coletivos com os individuais, cuidado que constitui um dos objetivos das organizações.

A remuneração estratégica abordada em estudos recentes desempenha importante papel nas empresas ao pagar incentivos e benefícios ao empregado e conseguir alinhar seu desempenho àquilo que esperam dele (O`TOOLE; LAWLER III, 2006). Esse tipo de remuneração pode se tornar um aliado na obtenção de resultados estratégicos, criando um diferencial competitivo significativo (NUNES; SOUZA NETO, 2008; WEBER; RAYNE, 1991).

Dessa forma, as corporações precisam desenvolver instrumentos que auxiliem a gestão de pessoas para satisfação e motivação das necessidades pessoais. Assim, mais que um simples plano de incentivo, é necessário um planejamento capaz de suprir tanto as necessidades dos indivíduos que nele se inserem quanto as do mercado atuante (KERBER; SCHNEIDER, 2012; ALVIM; ALVIM, 2011; GAULKE; NICOLETI, 2007; FOCHESATTO, 2002).

Para o empregado exercer suas funções com maior nível de produtividade e desempenho na execução de suas tarefas, é importante que esteja motivado. Além do salário, as empresas podem oferecer benefícios de diversos tipos para o alcance dessa motivação e até mesmo para o recrutamento de bons profissionais no mercado de trabalho e sua retenção. De acordo com Herzberg, Mausner e Snyderman (1953), funcionários motivados tendem a ser mais produtivos e criativos, e a remuneração é um dos fatores de maior de influência no comportamento.

Bergamini (2008) afirma que não há como motivar as pessoas sem considerar que elas são diferentes, e qualquer gestão irá fracassar se dirigi-las como se fossem iguais. Para o autor, cabe à empresa descobrir que práticas utilizar para motivar os colaboradores. De acordo com Bueno (2002), a motivação é um fator intrínseco e acontece apenas nos níveis mais elevados da hierarquia de Maslow 
- estima e autorrealização. Salário, condições de trabalho, recreações e lazer não geram motivação, apenas servem para prevenir a insatisfação.

Além disso, essas empresas devem compreender que cada indivíduo possui demandas e preferências distintas. Ou seja, as necessidades individuais variam de acordo com o estágio em que a pessoa se encontra, e isso deve ser estudado com maior profundidade, considerando as vantagens que um funcionário satisfeito com sua valorização e reconhecimento no âmbito organizacional traria de retorno à instituição (CAMINHA, 2012; KERBER; SCHNEIDER, 2012; GAULKE; NICOLETI, 2007; FOCHESATTO, 2002).

É nesse sentido que a implementação de práticas estratégicas deve ser compreendida de acordo com o contexto atual das organizações, pois se tais práticas não forem adaptadas ao contexto em que serão inseridas, as chances de se alcançarem os objetivos esperados ficam diminuídas. É sob a luz da Teoria da Contingência que essa afirmação se respalda. A partir de diversos conceitos já estabelecidos, entende-se que essa teoria estabelece que situações diferentes exigem práticas distintas, apregoando o uso das teorias tradicionais, comportamentais e de sistemas separadamente ou combinadas para resolver problemas das empresas. Isso demonstra que elas devem preocupar-se não só com a rentabilidade do empregado e com fatores contingenciais, mas sim com a necessidade e a satisfação pessoal dele e de todo o grupo de pessoas que nelas atuam.

A concepção de que necessidades organizacionais distintas carecem de práticas gerenciais consoantes à situação atual da empresa suporta que estudos acerca do ambiente organizacional que influenciam os colaboradores nele inseridos devem ser aprofundados. Nessa perspectiva, a questão que norteia esta pesquisa é: um plano de benefícios possui potencial de influenciar o aspecto motivacional dos empregados? Assim, o estudo objetiva averiguar, por meio da análise de conteúdo de um caso específico, em uma empresa do ramo metalúrgico, se o plano de benefícios individuais pode exercer influência sobre o aspecto motivacional dos colaboradores.

A pesquisa justifica-se por contribuir com os estudos já realizados e por analisar a relação entre o estímulo individual e o plano de remuneração estratégica, diante da contribuição que sistemas 
de remuneração indireta têm sobre o desempenho organizacional. Considera-se relevante também o estudo do plano de benefícios individuais, uma vez que a metalúrgica analisada não oferece nenhum tipo de benefício a seus colaboradores, e isso serve de sustentação para o conhecimento e aprofundamento do atual sistema gerencial adotado, bem como as expectativas e interesses dos membros que compõem essa companhia.

Ao considerar que a organização analisada se caracteriza como uma empresa familiar, a investigação dos interesses individuais dos colaboradores pode revelar pontos importantes para o mercado econômico brasileiro. Conforme Beuren, Carpes Dani e Beck (2014), em esfera global esse tipo de empresa se revela de forma significativa no contexto econômico-social como a modalidade mais simples e antiga das corporações.

\section{REMUNERAÇÃo}

De acordo com Bálkin e Gómez-Mejia (1987), a remuneração é um dos sistemas mais importantes e complexos da administração de recursos humanos. Ao mesmo tempo que estimula a busca por desempenhos cada vez melhores, alinha o comportamento das pessoas aos objetivos da empresa.

Chiavenato (1998) descreve que a remuneração geralmente é feita de muitas outras formas além do pagamento em salário e que parte considerável da remuneração total é constituída de benefícios sociais e de serviços sociais.

Questões a respeito do tema são discutidas em vários países do mundo, e diversos autores afirmam que esse conjunto de incentivos oferecidos pelas empresas serve não somente para manter os recursos humanos ativos e satisfeitos com suas atividades, mas também para fortalecimento da empresa como um sistema interligado e com um único objetivo, por meio do alinhamento de interesses (SHIM; LEE, 2003; CLASEN 2000; TOSI et al., 2000; AGGARWAL; SAMWICK, 1999; BÁLKIN; GÓMEZ-MEJIA, 1987).

Krauter (2009) exemplifica o conceito de remuneração de maneira sucinta, como mostra a Figura 1. 
Figura 1: O conceito de remuneração

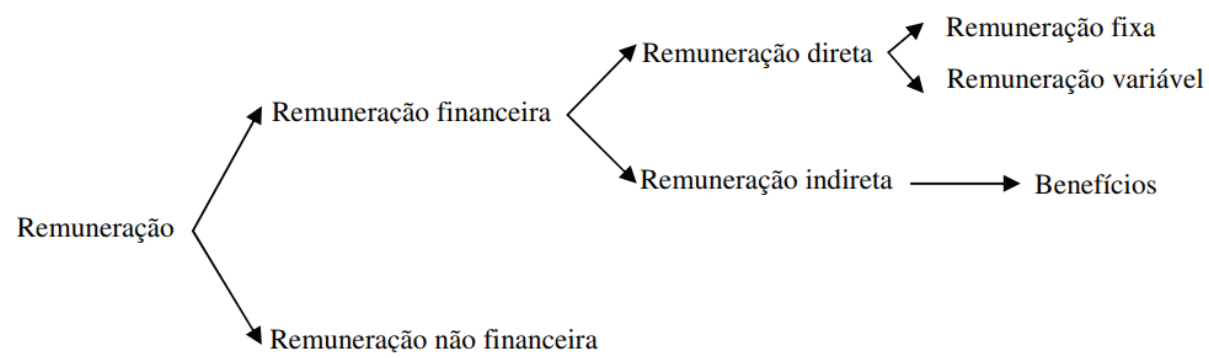

Fonte: Krauter (2009).

Considerando a existência de vasta literatura e de infindáveis terminologias (WOOD JR.; PICARELLI FILHO, 2004; MARRAS, 2001; FLANNERY; HOFRICHTER; PLATTEN, 1997; SCHUSTER; CARPENTER; KANE, 1997) acerca das formas de remuneração, de imediato deve-se conceituar remuneração como sendo a característica que define o trabalho assalariado, ou seja, é o que a empresa utiliza para trocar pelo serviço do empregado em determinado período. Abrange tudo aquilo que é recebido em troca da força de trabalho, envolvendo todas as formas de retorno financeiro e benefícios recebidos pelos colaboradores em uma relação de trabalho (MILKOVICH; NEWMAN, 1987; RIBEIRO, 2006).

Apesar dessa extensa literatura e suas ramificações, o presente artigo analisa a forma de benefícios flexíveis em contraponto ao aspecto motivacional, limitando-se à observação de planos de benefícios e a satisfação individual dos indivíduos estudados.

\subsection{Benefícios}

Marras (2001, p. 137) denomina benefício como “o conjunto de programas ou planos oferecidos pela empresa como complemento ao sistema de salários. O somatório compõe a remuneração do empregado". Nicoleti e Gaulke (2007) argumentam que os benefícios oferecidos pelas organizações podem ser subdivididos em compulsórios (ou legais) e espontâneos.

Os benefícios aos quais podem ser acrescidas outras vantagens são considerados salário indireto, ou seja, é uma remuneração fle- 
xível, a partir das alternativas disponíveis (WOOD JR.; PICARELLI FILHO, 2004).

Entendem-se como benefícios legais aqueles exigidos pela legislação trabalhista, previdenciária ou por convenções coletivas entre sindicatos, como $13^{\circ}$ salário, salário-família, salário-maternidade, férias remuneradas, repouso semanal remunerado, auxílio-doença, FGTS, adicional de $50 \%$ para horas extras, abono de $1 / 3$ sobre as férias, adicional de periculosidade etc. Já os espontâneos são os concedidos de forma natural sem exigência legal e visam a prover ao empregado e sua família certa condição de segurança e previdência em casos de imprevistos ou emergências, muitas vezes fora de seu controle ou vontade (MARRAS, 2001).

Os planos flexíveis pressupõem maturidade por parte da empresa e dos empregados, concedendo a estes o direito de escolher entre os melhores benefícios disponíveis ao seu perfil, condição familiar e estilo de vida (GHENO; BERLITZ, 2011). Chiavenato (2008) afirma que os benefícios sociais são planejados para auxiliar o colaborador em três áreas de sua vida: no exercício do cargo (gratificações, prêmios de produção, seguro de vida); fora do cargo, mas dentro da empresa (lazer, refeitório, transporte); ou fora dela, mas na comunidade (recreação, atividades comunitárias).

Para Flippo (1980, apud GHENO; BERLITZ, 2011), os benefícios são basicamente de três tipos: a) econômicos (propõem-se a oferecer certa segurança econômica adicional além do pagamento-base e dos bônus e pagamentos de incentivo, como pensões, seguro de vida, serviços de previdência, saúde e acidentes e cooperativas de crédito; b) recreativos (visam à diversão e a outras atividades sociais como esportes, acontecimentos sociais - bailes e piqueniques - e grupos de interesse especial - teatro e determinados passatempos); c) facilitadores (aqueles que, se o empregado não tivesse pela empresa, procuraria por si mesmo, como serviços médicos, habilitação, descontos em compras e cantinas, entre outros).

Fochesatto (2002) explica que para operacionalização dos benefícios, a organização abre uma conta de despesas flexíveis para cada empregado, frequentemente baseando-se num percentual sobre o salário, e estipula um preço para cada benefício. A partir disso os 
colaboradores selecionam as opções oferecidas até atingir o limite de porcentagem de salário.

Chiavenato (1999) elenca prós e contras dos benefícios flexíveis, conforme mostra o Quadro 1.

Quadro 1: Prós e contras da implantação de benefícios flexíveis

\begin{tabular}{|l|l|}
\hline Prós & Contras \\
\hline $\begin{array}{l}\text { Funcionários escolhem o pacote que } \\
\text { melhor satisfaça às necessidades pes- }\end{array}$ & \\
soais; & \\
Benefícios flexíveis ajudam a empresa a & $\begin{array}{l}\text { Funcionários podem fazer } \\
\text { escolhas inadequadas e não }\end{array}$ \\
uma força de trabalho mutável; & irão se sentir seguros quanto \\
Aumenta o envolvimento dos fun- & a emergências previsíveis; \\
cionários e suas famílias e melhora a & Os custos e a carga adminis- \\
compreensão dos benefícios; & trativa aumentam; \\
$\begin{array}{l}\text { Permitem a introdução de novos } \\
\text { benefícios a um custo menor; a nova } \\
\text { opção é meramente adicionada como adversa - os fun- } \\
\text { mais uma em uma ampla variedade de } \\
\text { elementos a serem escolhidos; }\end{array}$ & $\begin{array}{l}\text { cionários escolhem apenas } \\
\text { consequente utilização ele- } \\
\text { Limitam-se os custos, e a organização } \\
\text { tem a melhor forma de aplicação do } \\
\text { seu dinheiro; os funcionários escolhem } \\
\text { dentro dessa limitação. }\end{array}$ \\
\hline
\end{tabular}

Fonte: Adaptado de Chiavenato (1999).

Para Kerber e Schneider (2012), é importante atentar-se a dois aspectos na hora da implantação de um plano de benefícios flexíveis. O primeiro é que como a escolha passa a ser livre, isso acaba diluindo a preferência por determinados benefícios e pode suscitar uma perda de escala na negociação com os fornecedores de um benefício específico. $\mathrm{O}$ segundo é que a decisão requer acompanhamento, pois escolhas erradas dos colaboradores podem comprometer o caráter estratégico de alguns benefícios. 


\subsection{Estudos similares}

Estudos abrangentes acerca da relação entre planos de benefícios e motivação pessoal foram levantados. A importância desse exercício caracteriza-se pelo alinhamento de constructos e variáveis, servindo de sustentação consequente do objetivo do presente trabalho.

Fochesatto (2002) buscou verificar se os planos de incentivo e recompensa existentes em duas empresas do setor metalmecânico de Caxias do Sul (RS) contribuíam para o processo motivacional dos colaboradores. Em ambas, foram aplicados questionários aos níveis estratégico, tático e operacional (na primeira, 180 questionários, e na segunda, 173). O estudo concluiu que no nível estratégico da primeira empresa, os itens de maior valorização estavam mais ligados aos que complementavam o bem-estar do colaborador ou de seus familiares, tais como: alimentação na empresa (75,76\%); farmácias conveniadas $(69,70 \%)$; auxílio-creche $(66,67 \%)$; e previdência privada $(66,67 \%)$. Com relação ao nível tático, o item que apareceu com maior valorização foi a assistência médica $(68,18 \%)$, seguido por assistência hospitalar $(67,13 \%)$ e exames laboratoriais $(60,14 \%)$; e o nível operacional apresentou, por ordem, previdência privada $(63,76 \%)$, transporte $(63,40 \%)$ e assistência hospitalar $(59,36 \%)$. Em relação à segunda empresa analisada, para os funcionários do nível estratégico, dois itens são prioritários com $81,82 \%$ de incidência (assistências médica e hospitalar), seguidos de transporte $(77,27 \%)$. Os colaboradores do nível tático afirmaram que o convênio com farmácias era prioritário $(67,68 \%)$, seguida de assistência hospitalar $(65,66 \%)$ e ambulatório odontológico $(64,65 \%)$; e no nível operacional, o item mais valorizado foi o transporte de funcionários, com incidência de 63,52\%.

Reis Neto (2004) analisou a influência da remuneração variável na motivação e no desempenho dos colaboradores no trabalho em quatro empresas brasileiras de ramos diferentes, que foram escolhidas por possuírem Plano de Remuneração Variável consolidado e por apresentarem desempenho econômico financeiro expressivo em seu segmento. Aplicaram-se 315 questionários, cujo resultado revelou que, se fossem olhados apenas detalhes ou partes isoladas, não seria possível concluir sobre a preferência pelo plano de remuneração variável comparativamente à remuneração fixa tradicional. 
Se comparada com a remuneração fixa, a variável (mais remuneração fixa) foi preferida pela maioria dos entrevistados. Os pesquisados afirmaram que com o plano de remuneração variável há: maior incentivo para o esforço no trabalho; o desafio profissional é maior devido às metas; existe mais justiça na remuneração; o ganho total (R\$) é maior; a empresa cumpre fielmente o que promete; falta-se menos ao trabalho; a qualidade e a quantidade produzida são maiores; mais empenho para reduzir custos, aumentar os lucros e cumprir prazos; maior visão de longo prazo; maior empenho na satisfação dos clientes; mais facilidade para trabalhar em equipe; mais contribuição para melhorar o relacionamento com os colegas e com o chefe; mais cobrança de terceiros; cobra-se muito mais de si próprio e dos colegas e a avaliação de desempenho é mais justa. $\mathrm{O}$ autor concluiu que a sobrevivência da remuneração variável dentro das empresas depende do executivo principal, que é seu o grande fiador.

Gheno e Berlitz (2011) aplicaram um questionário aos funcionários do nível operacional de uma multinacional da região metropolitana de Porto Alegre. A empresa oferecia quatro programas de remuneração estratégica conhecidas por Grupo de Solução de Problemas, Ideias, Metas e Multifunção, e um pacote de benefícios, o qual era diferenciado de acordo com a função exercida. O estudo foi realizado com uma amostra não probabilística de 103 colaboradores com a finalidade de avaliar o nível de satisfação com relação aos planos oferecidos e revelou que a maioria considerava que tanto os programas de remuneração estratégica como o pacote de benefícios incentivavam seu desempenho em busca de melhores resultados. Os autores constataram também que o pacote de benefícios gera maior índice de satisfação do que os salários.

Caminha (2012) realizou um estudo de caso numa empresa pública da região sul do Brasil. Coletou 35 questionários e, conjuntamente com entrevistas e pesquisa documental, concluiu que a importância do sistema de benefícios oferecido foi considerada alta ou essencial para mais de $80 \%$ da amostra. O trabalho também revelou que alguns benefícios sensibilizam mais os colaboradores de forma geral, como o convênio de plano de saúde. Quanto às diferenças entre os sexos, para as mulheres o auxílio-creche/babá 
possuiu menor importância do que para os homens, mas, em contrapartida, para estes a participação nos lucros ocupou o segundo lugar entre os benefícios oferecidos, ao passo que para as mulheres apareceu apenas em quinto lugar, empatado com jornada de trabalho de seis horas e plano de previdência complementar (este ficou em nono lugar para os homens). Os benefícios menos sensíveis à amostra foram aqueles que ou não eram direito de todos ou não eram vantajosos para todos, como o caso do vale-transporte e do auxílio-creche/babá. As mulheres mostraram-se mais motivadas e deram importância maior aos benefícios do que os homens.

Carvalho e Menezes (2013), visando a observar as necessidades dos colaboradores de uma empresa de economia mista, bem como seus níveis de satisfação e compreensão do plano de benefícios recebidos, estudaram as respostas de 203 colaboradores. Concluíram que os benefícios mais representativos eram: assistência médica (46\%); vale-alimentação (17\%); previdência privada (15\%); participação nos lucros (8\%;); e abono do acordo coletivo (6\%). Em comparação com os demais, eles são os que agregam valor financeiro no salário ou à saúde do empregado. Observaram também que os benefícios mais solicitados foram: anuênio (bonificação de 1\% por ano de empresa), com 25\%; auxílio-creche para homens (apenas as mulheres empregadas na empresa têm esse benefício), com 14\%; e auxílio-educação para dependentes (filhos e cônjuge não podem usufrui-lo), com $13 \%$. Os resultados da pesquisa revelaram ainda que o empregado é mais sensível a benefícios que agregam valor direto ao salário e que atendam a suas necessidades; os demais ficaram em segundo plano.

\section{Procedimentos metodológicos}

No que se refere aos objetivos, esta pesquisa se classifica como descritiva, pois, conforme apresenta Gil (1999), tem como objetivo principal descrever características de determinada população e estabelecer a relação entre variáveis. Para Andrade (2003, p. 124), nesse tipo de pesquisa "os fatos são observados, registrados, analisados, classificados e interpretados, sem que o pesquisador interfira neles".

Quanto à abordagem, a pesquisa pode ser enquadrada como qualitativa. De acordo com Raupp e Beuren (2009, p. 92), “na pesquisa qualitativa concebem-se análises mais profundas em relação 
ao fenômeno que está sendo estudado". Uma vez que "essa abordagem visa a destacar características não observadas por meio de um estudo quantitativo". Este estudo não se utiliza de instrumentos estatísticos na obtenção e análise dos resultados, configurando-se, portanto, em qualitativo.

Esta pesquisa enquadra-se também como bibliográfica, pois, conforme Raupp e Beuren (2009), o material utilizado como base abrange todo o referencial teórico já publicado no que se refere ao tema de estudo. A pesquisa bibliográfica foi utilizada por meio do uso de artigos, livros, monografias e dissertações.

O trabalho proposto consistiu de um estudo de caso em uma empresa do ramo metalúrgico com controle familiar e foi desenvolvido a partir de duas etapas. A primeira partiu de um levantamento com o administrador a fim de verificar se a companhia oferecia um plano de incentivos e, caso houvesse, descrevê-lo. Na segunda etapa foi aplicado questionário aos níveis estratégico, tático e operacional com a finalidade de detectar a relação entre motivação pessoal e implantação de um plano de benefícios. A amostra constitui-se em probabilística, pois, conforme ressaltam Prodanov e Freitas (2013), nesse tipo de amostra qualquer elemento da população-alvo tem probabilidade de fazer parte dela, diferente de zero.

O questionário elaborado não continha identificação do respondente e possuía algumas questões para verificação do perfil do colaborador como sexo, idade, tempo de empresa, escolaridade e estado civil (algumas abertas e por outras fechadas). As questões abertas, a partir de Sommer e Sommer (1997), mostram frequentemente mais respeito à opinião das pessoas, deixando-as classificar as respostas como positivas, negativas ou neutras. Já as abertas estabelecem um clima receptivo entre pesquisador e respondente e capturam justamente aquelas opiniões não cobertas pelos itens fechados (GÜNTER, 2003).

O questionário foi desenvolvido a partir do referencial teórico sobre o tema e constituído por oito perguntas, conforme mostrado no Quadro 2. 
Quadro 2: Questionário aplicado

\begin{tabular}{|l|l|}
\hline Questão 1 & Idade \\
\hline Questão 2 & Sexo \\
\hline Questão 3 & Estado civil \\
\hline Questão 4 & Tempo de experiência profissional \\
\hline Questão 5 & $\begin{array}{l}\text { Gostaria de poder optar por qual benefício receber da } \\
\text { empresa? }\end{array}$ \\
\hline Questão 6 & $\begin{array}{l}\text { Qual seria o benefício mais importante a ser oferecido } \\
\text { pela empresa? }\end{array}$ \\
\hline Questão 7 & $\begin{array}{l}\text { Qual o nível de importância dos benefícios flexíveis para a } \\
\text { sua motivação pessoal? }\end{array}$ \\
\hline Questão 8 & $\begin{array}{l}\text { Preenchimento de tabela com "X" para indicar o nível de } \\
\text { importância individual sobre os benefícios mais citados na } \\
\text { literatura nacional, conforme representado na Tabela 1. }\end{array}$ \\
\hline
\end{tabular}

Fonte: Elaborado pelos autores.

A Tabela 1 traz os questionamentos e respostas acerca do nível de importância atribuído aos benefícios apresentados.

Tabela 1: Nível de importância atribuído aos benefícios

\begin{tabular}{lllll}
\hline Benefícios & Nenhuma & Baixa & Média & Alta \\
\hline Convênio de plano de saúde & 0 & 1 & 5 & 17 \\
Inclusão de familiares no plano de saúde & 1 & 2 & 7 & 13 \\
Vale-refeição/alimentação & 2 & 4 & 5 & 12 \\
Campanha de vacinaça anual contra a & 2 & 3 & 7 & 11 \\
gripe & 5 & 1 & 6 & 11 \\
Vale-transporte & 4 & 5 & 4 & 10 \\
Jornada de trabalho flexível & 1 & 5 & 9 & 8 \\
Convênio de plano odontológico & 7 & 5 & 3 & 8 \\
Programa de pós-graduação & 5 & 4 & 6 & 8 \\
Licença-prêmio & 3 & 2 & 10 & 8 \\
Festa para empregados & 2 & 5 & 8 & 8 \\
Gratificação semestral & 3 & 5 & 8 & 7 \\
Plano de previdência complementar & 3 & 8 & 5 & 7 \\
Seguro de vida & 2 & 5 & 10 & 6
\end{tabular}




\begin{tabular}{lllll}
\hline Benefícios & Nenhuma & Baixa & Média & Alta \\
\hline Auxílio-creche/babá & 7 & 5 & 5 & 6 \\
Seguro de acidentes pessoais & 4 & 6 & 7 & 6 \\
Licença não remunerada a pedido - LTI & 9 & 6 & 4 & 4 \\
Programa de línguas estrangeiras & 9 & 4 & 8 & 2 \\
Cesta básica & 6 & 7 & 8 & 2 \\
Ginástica laboral & 11 & 7 & 5 & 0 \\
Auxílio-funeral & 12 & 6 & 5 & 0 \\
\hline
\end{tabular}

Fonte: Elaborado pelos autores.

A empresa analisada conta com 26 colaboradores, o que, de acordo com classificação utilizada pela área de pesquisa do Sebrae, a caracteriza como de pequeno porte. A amostra foi composta por 23 colaboradores, o equivalente a $88 \%$ da população. Dos que não responderam, dois estavam em férias, e um na perícia médica. A coleta iniciou-se no dia 21 de janeiro de 2016 e terminou no dia 26 do mesmo mês.

Os dados foram processados com o uso de recursos computacionais por meio de planilhas do programa Excel e analisados e classificados de acordo com as questões aplicadas. Segundo Mattar (1998), o processamento compreende os passos necessários para transformar os dados brutos em trabalhados para realizar análises e interpretações.

\section{APRESENTAÇÃo E ANÁlise dos RESUltados}

\subsection{Caracterização da empresa em estudo}

A empresa estudada foi fundada em 1998 em Florianópolis (SC) e iniciou suas atividades somente com a prestação de serviços de torno e solda. Desde o segundo semestre de 2006, mudou-se para o município de Palhoça (SC). Possui mais de $2.000 \mathrm{~m}^{2}$ de área construída e utiliza máquinas de médio e grande porte com alta tecnologia.

No que concerne à estrutura organizacional, o diretor-superintendente é quem comanda a empresa. $\mathrm{Na}$ área administrativa atuam nove pessoas (um administrador, dois gerentes financeiros, um gerente comercial, três vendedores, um comprador e um auxiliar 
de caixa e escritório). A produção conta com 14 pessoas (um diretor, um chefe de operários, um operador de máquina e 11 auxiliares de produção). A Figura 1 traz o organograma organizacional.

Figura 2: Organograma da empresa analisada

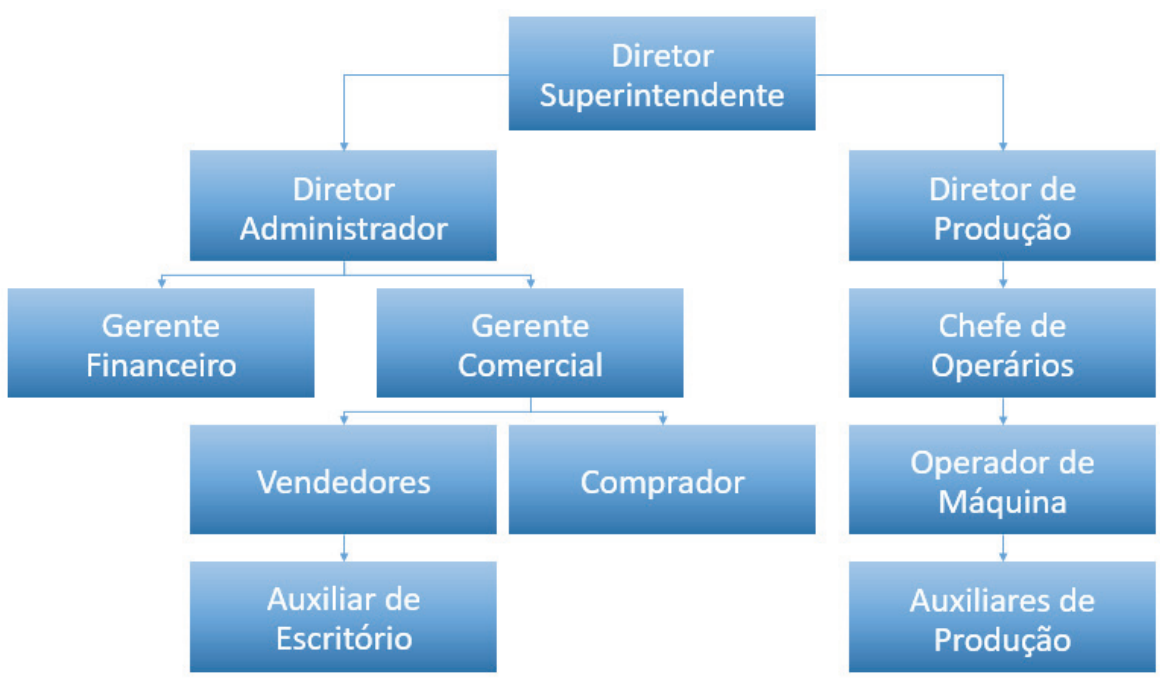

Fonte: Dados da empresa (2014).

As primeiras informações obtidas com o questionário foram sobre o perfil dos respondentes: $74 \%$ são homens (17), ao passo que a participação feminina (6) representa $26 \%$. Os dados mostram que $52 \%$ estão na faixa etária entre 20 e 30 anos; $26 \%$, têm entre 31 e 40 anos; 9\% entre 41 a 50 anos; e acima de 51 anos, 13\% - esses números revelam que a empresa é constituída por um quadro funcional mais jovem. Quando analisada a variável estado civil, constata-se que $61 \%$ são casados. Dos respondentes, $13 \%$ possuem até 5 anos de experiência na área; 30\% entre 5 a 10; $26 \%$ entre 10 e 15; $13 \%$ entre 15 e $20 ; 4 \%$ entre 20 a 25; $4 \%$ entre 30 a 35; e $9 \%$ possuem mais de 40 anos de experiência na profissão.

\subsection{Os benefícios e a motivação}

A quinta questão buscou verificar se os colaboradores gostariam de optar sobre os benefícios recebidos. Nesse aspecto, os 23 
respondentes sinalizaram o desejo de ter a liberdade de escolha sobre o tipo de benefício que receberiam, ou seja, preferem optar por um benefício particular, em detrimento de outro já estabelecido pela organização.

Em seguida, foi questionado a respeito de quais seriam esses benefícios. As respostas podem ser alinhadas à situação vivida pela organização, que não oferece nenhum benefício. Assim, destaca-se que os objetivos dos empregadores e empregados não estão equiparados, pois, de um lado, tem-se a percepção de que não é preciso que haja benefícios, e de outro, a plena necessidade deles.

A pergunta 6 do questionário deixou espaço para identificação de qual seria o benefício mais importante e atraente a ser oferecido aos empregados, caso houvesse um plano de benefícios flexíveis na empresa. O resultado mostrou que $65 \%$ apontaram o plano de saúde, e o segundo mais citado foi o vale-alimentação, com 14\%. Essa resposta encontra-se em sintonia com os achados de Caminha (2012), Carvalho e Menezes (2013) e de Gheno e Berlitz (2011), que, em seus estudos, também constataram a preferência dos entrevistados pelos benefícios diretamente ligados à saúde. Essa preocupação pode ser um reflexo da dificuldade enfrentada para acessá-la.

\subsection{Benefícios e sua relação com a motivação}

A análise da importância atribuída aos benefícios e a relação deles com a motivação pessoal (questão 7) encontram-se estratificadas nos parágrafos seguintes. Visando a compreender melhor eventuais divergências, elas foram segregadas por idade, gênero, estado civil e tempo de experiência. As respostas foram dispostas conforme os níveis de importância percebida: nenhuma, baixa, média e alta importância.

Na Figura 3, pode-se perceber que a idade dos empregados possui relação com a percepção sobre a importância dos benefícios na motivação. No entanto, deve-se reparar que os maiores níveis de concentração das respostas estão de alta a média importância e que isso se deve especialmente aos colaboradores de 20 a 30 anos de idade. Verifica-se também que nenhum dos respondentes atribui valor zero aos benefícios e sua relação com a motivação pessoal. A média percepção de importância da faixa etária acima de 50 anos 
está atrelada à opinião tanto dos colaboradores quanto do diretor-superintendente, uma vez que dessas três respostas, duas são da hierarquia de nível operacional e uma de nível estratégico.

Figura 3: Importância atribuída aos benefícios flexíveis de acordo com a faixa etária

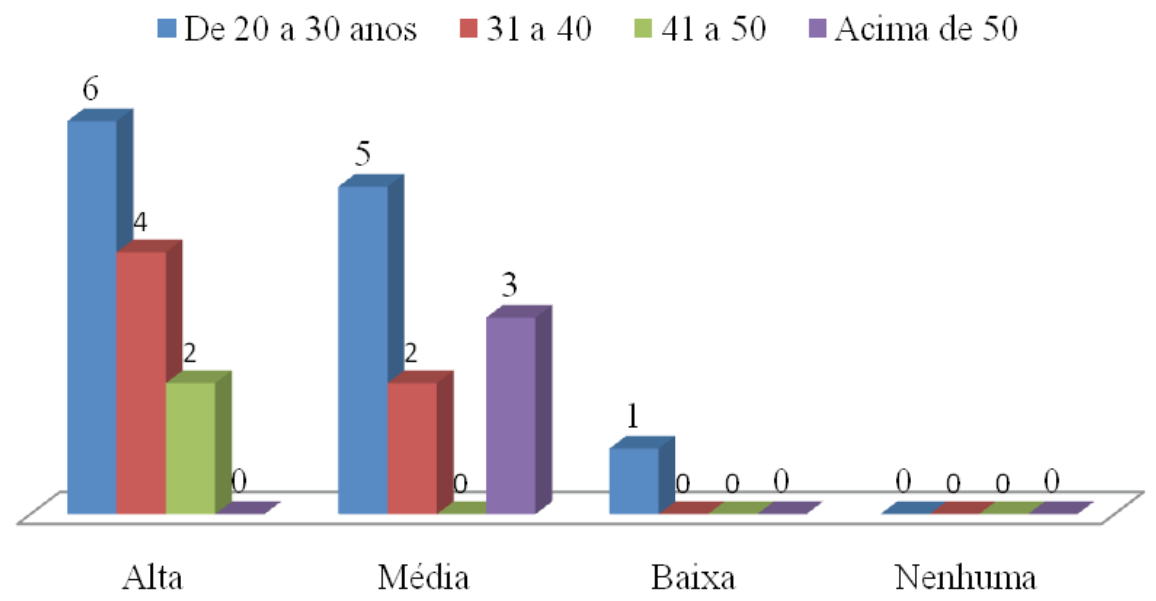

Fonte: Elaborado pelos autores.

Quando a amostra é estratificada por sexo, constata-se que 53\% dos homens e $50 \%$ das mulheres entendem que os benefícios flexíveis exerceriam importante papel na motivação pessoal e no empenho para buscar o alcance dos propósitos da organização.

Sob a perspectiva do estado civil do entrevistado, percebe-se que a importância dos benefícios para a motivação pessoal dos casados é superior (61\%) à verificada entre os solteiros (39\%).

Ao observar a opinião dos participantes de acordo com o tempo de experiência em suas funções, o números revelam que aqueles que possuem até 20 anos de vivência profissional atribuem maior importância dos benefícios para aumentar sua motivação; no entanto, a concentração de respostas se deu no nível de média importância. A Figura 4, a seguir, ilustra esses dados. 
Figura 4: Importância atribuída aos benefícios flexíveis de acordo com a experiência

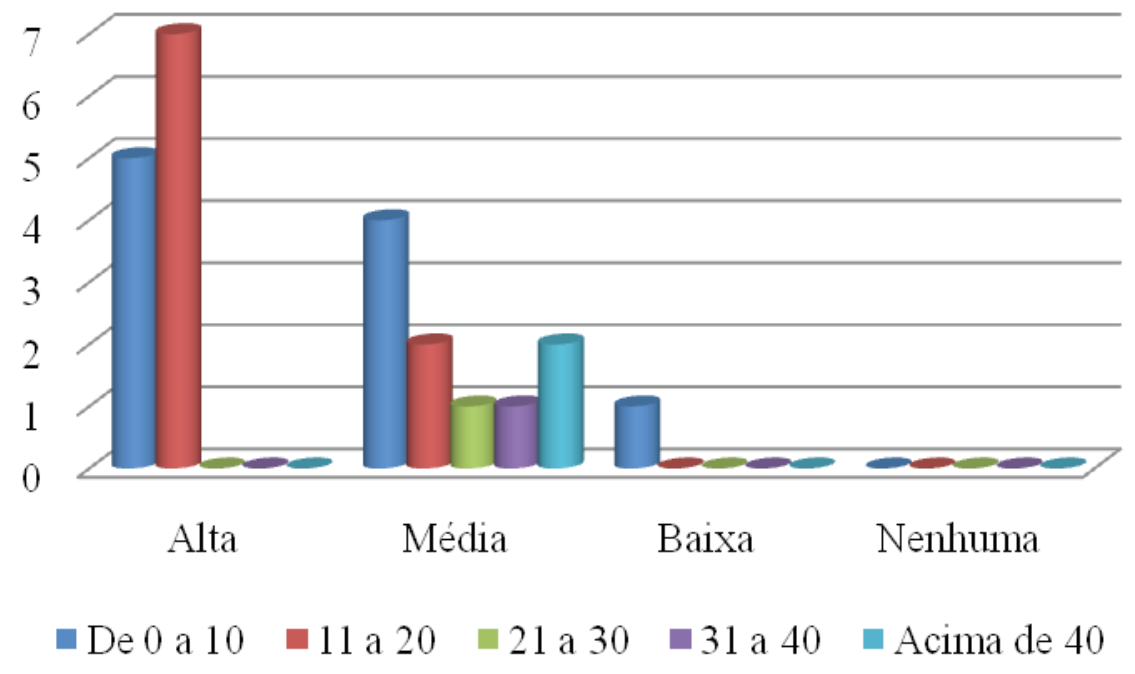

Fonte: Elaborado pelos autores.

No presente estudo, quando relacionadas as respostas de todos os 23 respondentes, sem classificação por ordem de sexo, idade, experiência ou qualquer outra variável, depreende-se que 52\% consideram alta a importância dos benefícios flexíveis para o nível de motivação e consequente desempenho pessoal. Observam-se os resultados na Figura 5.

Merece destaque o fato de que $96 \%$ dos pesquisados consideram alta ou média a importância dos benefícios sobre o seu nível de motivação para exercerem suas funções. Esses resultados estão alinhados com os encontrados por Reis Neto (2004), Caminha (2012) e Fochesatto (2002).

Assim, como a empresa objeto desta pesquisa ainda não possui benefícios implantados, esse grande índice de importância percebida seguramente constitui-se num argumento sólido para, no mínimo, analisar com carinho a implementação deles. 
Figura 5: Nível geral de relevância dos benefícios flexíveis
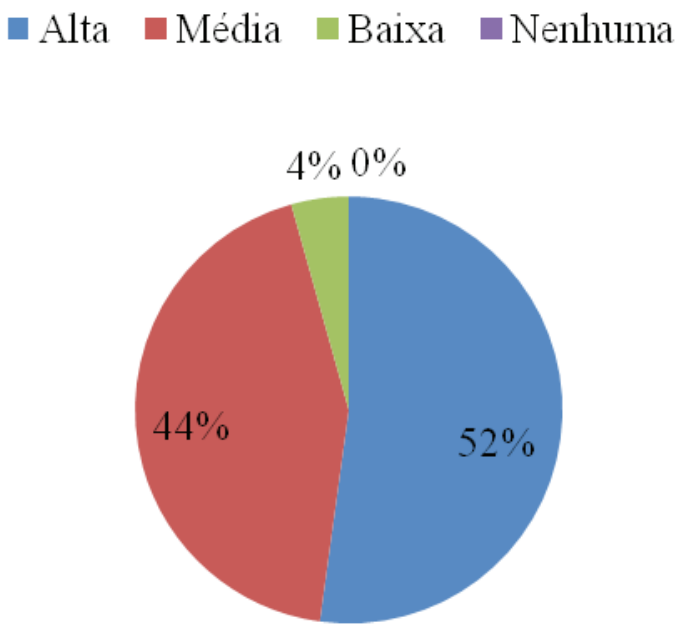

Fonte: Elaborado pelos autores.

\subsection{Níveis de importância dos benefícios}

O último item do questionário deixou espaço para que os respondentes estabelecessem níveis de importância em relação aos benefícios mais abordados na literatura (nenhuma, baixa, média e alta importância). A Tabela 2 traz a percepção relativa dos empregados.

A Tabela 2 está ordenada de forma decrescente de acordo com o nível de importância atribuído a cada benefício. Nela fica evidente a importância do plano de saúde dos respondentes $(74 \%)$ e dos familiares (57\%). Em seguida, aparece a preocupação com o vale-alimentação/refeição (52\%), campanha de vacinação anual contra a gripe e vale-transporte (empatados com $48 \%$ ) e jornada de trabalho flexível (43\%).

Em se tratando dos benefícios considerados com nenhuma ou pouca importância, os cinco mais citados foram auxílio-funeral, com mais da metade das respostas (52\%), ginástica laboral (48\%), licença não remunerada a pedido e programa de línguas estrangeiras (ambos com um percentual de 39\%), e programa de pós-graduação e auxílio-creche/babá (ambos com 30\%). 
Tabela 2: Grau de importância atribuído aos benefícios

\begin{tabular}{|c|c|c|c|c|}
\hline Benefícios & Nenhuma $\%$ & Baixa \% & Média \% & Alta $\%$ \\
\hline \multirow{5}{*}{$\begin{array}{l}\text { Convênio de plano de saúde } \\
\text { Inclusão de familiares no plano } \\
\text { de saúde } \\
\text { Vale-refeição/alimentação } \\
\text { Campanha de vacinação anual } \\
\text { contra a gripe } \\
\text { Vale-transporte }\end{array}$} & $0 \%$ & $4 \%$ & $22 \%$ & $74 \%$ \\
\hline & $4 \%$ & $9 \%$ & $30 \%$ & $57 \%$ \\
\hline & $9 \%$ & $17 \%$ & $22 \%$ & $52 \%$ \\
\hline & $9 \%$ & $13 \%$ & $30 \%$ & $48 \%$ \\
\hline & $22 \%$ & $4 \%$ & $26 \%$ & $48 \%$ \\
\hline Jornada de trabalho flexível & $17 \%$ & $22 \%$ & $17 \%$ & $43 \%$ \\
\hline Convênio de plano odontológico & $4 \%$ & $22 \%$ & $39 \%$ & $35 \%$ \\
\hline Programa de pós-graduação & $30 \%$ & $22 \%$ & $13 \%$ & $35 \%$ \\
\hline Licença-prêmio & $22 \%$ & $17 \%$ & $26 \%$ & $35 \%$ \\
\hline Festa para empregados & $13 \%$ & $9 \%$ & $43 \%$ & $35 \%$ \\
\hline \multirow{3}{*}{$\begin{array}{l}\text { Gratificação semestral } \\
\text { Plano de previdência comple- } \\
\text { mentar } \\
\text { Seguro de vida }\end{array}$} & $9 \%$ & $22 \%$ & $35 \%$ & $35 \%$ \\
\hline & $13 \%$ & $22 \%$ & $35 \%$ & $30 \%$ \\
\hline & $13 \%$ & $35 \%$ & $22 \%$ & $30 \%$ \\
\hline Dias de prêmio-assiduidade & $9 \%$ & $22 \%$ & $43 \%$ & $26 \%$ \\
\hline Auxílio-creche/babá & $30 \%$ & $22 \%$ & $22 \%$ & $26 \%$ \\
\hline \multirow{4}{*}{$\begin{array}{l}\text { Seguro de acidentes pessoais } \\
\text { Licença não remunerada a pedi- } \\
\text { do - LTI } \\
\text { Programa de línguas estrangei- } \\
\text { ras } \\
\text { Cesta básica }\end{array}$} & $17 \%$ & $26 \%$ & $30 \%$ & $26 \%$ \\
\hline & $39 \%$ & $26 \%$ & $17 \%$ & $17 \%$ \\
\hline & $39 \%$ & $17 \%$ & $35 \%$ & $9 \%$ \\
\hline & $26 \%$ & $30 \%$ & $35 \%$ & $9 \%$ \\
\hline Ginástica laboral & $48 \%$ & $30 \%$ & $22 \%$ & $0 \%$ \\
\hline Auxílio-funeral & $52 \%$ & $26 \%$ & $22 \%$ & $0 \%$ \\
\hline
\end{tabular}

Fonte: Elaborado pelos autores.

As informações contidas na Tabela 2 refletem as expectativas e sentimentos dos colaboradores que no momento não recebem nenhum tipo de benefício e confirmam a relação com estudos anteriores segundo os quais há uma relação direta entre os benefícios flexíveis e a motivação pessoal dos colaboradores dentro do clima organizacional. Além disso corroboram as teorias de autores que há muito se dedicam ao processo de planejamento estratégico e os incentivos individuais. É o caso da Teoria da Contingência, que 
esclarece que a situação organizacional depende de vários fatores ou contextos em que estas operam.

Mais uma vez, a exemplo dos demais enfoques analisados nesta pesquisa, os achados estão em sintonia com os de Fochesatto (2002), reforçando a importância atribuída pelas pessoas ao seu bem-estar mais básico: a saúde. Talvez este seja reflexo do momento e situação em que se encontra o acesso à saúde em caso de necessidade.

\section{ConClusões}

Este estudo buscou verificar se o plano de benefícios individuais possui um aspecto motivacional para os colaboradores de uma metalúrgica com controle do tipo familiar. Para tanto, abordaram-se aspectos teóricos relacionados à forma de benefícios flexíveis em contraponto ao aspecto motivacional, limitando-se à observação de planos de benefícios e a satisfação individual.

Com base na análise dos dados, conclui-se que o benefício percebido como mais importante é o plano de saúde, representando $65 \%$ da amostra, e que $100 \%$ dos respondentes gostaria de ter liberdade de escolha no momento de receber benefícios flexíveis. Os considerados menos importantes foram o auxílio-funeral e a ginástica laboral. Isso talvez possa ser explicado pelo fato de que a média de idade dos envolvidos ainda é baixa.

Constatou-se também que os jovens atribuíram maior importância aos benefícios. Isso, de acordo com Fochesatto (2002), talvez se justifique em função do seu espírito mais irrequieto e da sua busca incessante pela inovação dentro das organizações. Outro aspecto que requer reflexão diz respeito ao fato de que as pessoas casadas atribuem maior importância ao papel dos benefícios na sua motivação pessoal.

Dessa forma, ficou claro que a importância percebida pelos funcionários sobre o papel dos benefícios na sua motivação e, consequentemente, no empenho e desempenho organizacional é significativa. Como a empresa ainda não possui nenhum plano de benefícios em vigor, resta a reflexão sobre a viabilidade operacional e financeira de sua implementação.

Ao se considerarem os custos de implantação, o tempo despendido para planejamento e execução da prática e os fatores que 
possam surgir durante o processo de adequação, a aplicabilidade dessa estratégia em algumas empresas torna-se difícil. No entanto, é perceptível que os benefícios concedidos pelas corporações não vêm atendendo de maneira eficaz a seus colaboradores e que por esse motivo tornam-se cada vez mais importantes estudos sobre a motivação e necessidade individual do ser humano como relação direta ao desempenho individual e organizacional (CAMINHA, 2012; ALVIM; ALVIM, 2011; GHENO; BERLITZ, 2011; ASSALIN; ARANHA, 2010; GAULKE; NICOLETI, 2007; REIS NETO, 2004; FOCHESATTO, 2002).

Dessa maneira, pesquisas sobre a motivação e necessidade individual do ser humano como relação direta ao desempenho individual e organizacional são necessárias e estão cada vez mais aprofundada; no entanto, ainda há o que descobrir e estudar (FOCHESATTO, 2002; MINTZBERG; AHLSTRAND; LAMPEL, 2000; CHIAVENATO, 1999).

Como limitações da pesquisa, pode-se destacar a substantiva diferença entre o número de participantes homens e mulheres, bem como os poucos níveis hierárquicos e pessoas em cada um deles. Esses aspectos restringem a análise de percepção dos sexos e níveis hierárquicos diante o tema.

Por fim, sugere-se para futuras pesquisas a realização de estudos sobre a relação entre benefícios flexíveis e a motivação dos colaboradores em empresas de ramos e portes distintos, bem como estratificando por níveis hierárquicos e relacionais (dono ou empregado), o que permitirá novos olhares e constatações sobre o tema.

\section{REFERÊNCIAS}

ALVIM, L. R. de A.; ALVIM, S. J. T. Estudo dos efeitos do pacote de benefícios sociais sobre a motivação e produtividade dos colaboradores em uma empresa do interior. In: CONGRESSO VIRTUAL BRASILEIRO DE ADMINISTRAÇÃO, VIII., 2-4 dez. 2011. Anais... [S.1.]: Convibra, 2011.

AGGARWAL, R. K.; SAMWICK, A. A. Executive compensation, strategic competition and relative performance evaluation: theory and evidence. The Journal of Finance. Dartmouth College, v. 54, n. 6, p. 1999-2043, 1999.

ANDRADE, M. M. de. Introdução à metodologia do trabalho científico: elaboração de trabalhos na graduação. 3. ed. São Paulo: Atlas, 2003. 
ASSALIN, F. M; ARANHA, F. B. Benefícios como parte de incentivo a remuneração nas organizações. 73 f. Trabalho de Conclusão de Curso (Bacharel em Administração de Empresas) - Faculdade Cenecista de Capivari. SP. p. 73. 2010.

BÁLKIN, D. B.; GÓMEZ-MEJIA, L. R. Toward a contingency theory of compensation strategy. Strategic Management Journal, v. 8, n. 2, p. 169-182, mar/apr. 1987.

BERGAMINI, C. W. Motivação nas organizações. 5. ed. São Paulo: Atlas, 2008.

BEUREN, I. M.; CARPES DANI, A.; BECK, F. Relação entre as práticas do Board Interlocking e características de empresas de estrutura de propriedade familiar com ações mais negociadas na BM\&FBovespa. Revista Eletrônica de Ciência Administrativa, Campo Largo - PR, Brasil. v. 13, n. 3, p. 339-355. 2014.

BUENO, M. As teorias de Motivação Humana e sua contribuição para a empresa humanizada. BUENO, M. As teorias de Motivação Humana e sua contribuição para a empresa humanizada. Revista do Centro de Ensino Superior de Catalão - CESUC, Catalão. ano 4, n. 06, p. 1-25, 1ํ sem. 2002.

CAMINHA, G. M. A motivação e o plano de benefícios para os funcionários de uma instituição financeira pública. 52 f. Trabalho de Conclusão de Curso (Pós-Graduação em Administração Pública) - Universidade Federal do Rio Grande do Sul, Porto Alegre, 2012.

CARVAlHO, R. A. S.; MENEZES, N. A. Benefícios sociais: valor e satisfação sob a ótica dos empregados. [On-line]. Disponível em: <http://www.academia. edu/8736283/BENEF\%C3\%8DCIOS_SOCIAIS_VALOR_E_SATISFA\%C3\%87\%C3\%83O_ SOB_A_\%C3\%93TICA_DOS_EMPREGADOS>. Acesso em: 15 jan. 2016.

CHIAVEnATO, I. Teoria Geral de Administração. 4. ed. Rio de Janeiro: Campus, 1998.

. Gestão de Pessoas: o novo papel dos recursos humanos nas organizações. Rio de Janeiro: Elsevier, 1999.

. Gestão de Pessoas: o novo papel dos recursos humanos nas organizações. 3.ed. - Rio de Janeiro: Elsevier, 2008.

. Teoria Geral da Administração: Abordagens prescritivas e normativas da Administração. Rio de Janeiro: Editora Campus, 2001.

CLASEN, E. Um estudo sobre o estabelecimento de metas e sua aferição nos programas de remuneração variável em companhias de capital aberto de Joinville/SC. 123 f. Dissertação (Mestrado em Administração) - Universidade Federal de Santa Catarina, Florianópolis, 2000.

FLANNERY, T. P.; HOFRICHTER, D.; PLATTEN, P. E. Pessoas, desempenho e salários: as mudanças na forma de remuneração nas empresas. Tradução de Bazán Tecnologia e Linguística. São Paulo: Futura, 1997.

FOCHESATTO, S. A. Os planos de incentivos e recompensas como fatores de motivação: estudos de caso nas duas maiores empresas do ramo metal-mecânico de Caxias do Sul. 136 f. Dissertação (Mestrado em Administração) - Universidade Federal do Rio Grande do Sul, Porto Alegre, 2002. 
GAULKE, C. N.; NICOLETI, G. G. Benefícios: usado como fator motivacional pela empresa Karsten S/A no setor tecelagem $111^{\circ}$ turno. Revista Interdisciplinar Científica Aplicada, Blumenau, v. 1, n. 2, p. 1-15, 1ำ sem. 2007.

GHENO, R; BERLITZ, J. Remuneração estratégica e pacote de benefícios: um estudo de caso aplicado ao nível operacional de uma multinacional. Rev. Adm. UFSM, Santa Maria, v. 4, n. 1, p. 268-287 maio/ago. 2011.

GIL, A. C. Métodos e técnicas de pesquisa social. 5. ed. São Paulo: Atlas, 1999.

GUNTER, H. Como elaborar um questionário (Série Planejamento de pesquisa nas ciências sociais, N. 1). Brasília, DF: UnB, 2003.

HERZBERG, F.; MAUSNER, B.; SNYDERMAN, B. B. The Motivation to Work. New York: John Wiley \& Sons, 1953.

GÜNTHER, H. Como elaborar um questionário. Série Planejamento de Pesquisa nas Ciências Sociais, nº 01. Brasília: UnB, Laboratório de Psicologia Ambiental, 2003.

KRAUTER, E. As contribuições do sistema de remuneração dos executivos para o desempenho financeiro: Um estudo com empresas industriais brasileiras. $180 \mathrm{f}$. Tese (Doutorado em Administração) - Universidade de São Paulo, São Paulo, 2009.

KERBER, S.; SCHNEIDER, A. M. Benefícios flexíveis. Revista Destaques Acadêmicos, CGO/ UNIVATES, Lajeado/RS - Brasil. v. 4. n. 1, p.29-38. 2012.

MARRAS, J. P. Administração de Recursos Humanos: do operacional ao estratégico. 3. ed. São Paulo: Futura, 2001.

MATTAR, F. N. Pesquisa de marketing. São Paulo: Atlas, 1998.

MILKOVICH, G. T.; NEWMAN, J. M. Compensation. 2. ed. Texas: Business Publications, 1987. MINTZBERG, H.; AHLSTRAND, B.; LAMPEL, J. Safári de estratégia: um roteiro pela selva do planejamento estratégico. Porto Alegre: Bookman, 2000.

NUNES, A. L.; SOUZA NETO, S. P. A Avaliação de desempenho baseada nos pilares da remuneração por competências: um estudo de caso. Sociedade, Contabilidade e Gestão, Rio de Janeiro, v. 3, n. 1, p. 97-111, jan./jun. 2008.

O'TOOLE, J.; LAWLER III, E. E. The new american workplace. New York: Palgrave, 2006.

PRODANOV, C. C.; FREITAS, E. C. Metodologia do trabalho científico: Métodos e técnicas da pesquisa e do trabalho Acadêmico. [Recurso eletrônico]. 2. ed. Novo Hamburgo: Feevale, 2013.

RAUPP, F. M.; BEUREN, I. M. metodologia da pesquisa aplicável às ciências sociais. In: BEUREN, I. M. (Org.) Como elaborar trabalhos monográficos em contabilidade: teoria e prática. 3. ed. 4. reimpr. São Paulo: Atlas, 2009. p. 76-97.

REIS NETO, M. T. A remuneração variável na percepção dos empregados e suas consequências na motivação e no desempenho. 288 f. Tese (Doutorado em Administração) -Universidade Federal de Minas Gerais, Belo Horizonte, 2004.

RIBEIRO, A. Gestão de pessoas. São Paulo: Saraiva, 2006. 
SCHUSTER, J. P.; CARPENTER, J.; KANE, M. Pa. O poder do gerenciamento transparente. São Paulo: Futura, 1997.

SHIM, E.; LEE, J. A canonical analysis of CEO compensation and corporate performance in the service industry. Review of Accounting \& Finance, University of Wollongong Australia. v. 2, n. 3, p. 72-90, 2003.

SOMMER, B; SOMMER, R. A pratical guide to behavioral research: Tools and techniques. 4 ed. New York: Oxford University Press, 1997.

TOSI, H. L. et al. How much does performance matter? A meta-analysis of CEO pay studies. Journal of Management, University of Florida. v. 26, n. 2, p. 301-339, 2000.

WEBER, C. L.; RAYNE, S. L. Effects of compensation strategy on job pay decision. Academy of Management Journal, Briarcliff Manor, v. 34, n. 1, p. 86-109, 1991.

WOOD JR., T.; PICARELLI FILHO, V. Remuneração estratégica: a nova vantagem competitiva. 3. ed. São Paulo: Atlas, 2004.

Recebido em: 21-11-2016

Aprovado em: 24-4-2017

Avaliado pelo sistema double blind review.

Editor: Elmo Tambosi Filho

Disponível em http://mjs.metodista.br/index.php/roc 